\title{
Impact of WHO Hand Hygiene Improvement Program Implementation: A Quasi-Experimental Trial
}

\author{
Farinaz Farhoudi, ${ }^{1}$ Anahita Sanaei Dashti, ${ }^{2}$ Minoo Hoshangi Davani, ${ }^{1}$ Nadiyeh Ghalebi, \\ Golnar Sajadi, ${ }^{2}$ and Raziyeh Taghizadeh ${ }^{1}$ \\ ${ }^{1}$ Infection Prevention and Control Unit, Nemazee Hospital, Shiraz University of Medical Sciences, Shiraz, Iran \\ ${ }^{2}$ Professor Alborzi Clinical Microbiology Research Center, Nemazee Hospital, Shiraz University of Medical Sciences, Shiraz, Iran \\ Correspondence should be addressed to Anahita Sanaei Dashti; anahita_sam@yahoo.com
}

Received 18 July 2016; Accepted 6 November 2016

Academic Editor: Tessa Keegel

Copyright (C) 2016 Farinaz Farhoudi et al. This is an open access article distributed under the Creative Commons Attribution License, which permits unrestricted use, distribution, and reproduction in any medium, provided the original work is properly cited.

\begin{abstract}
Objectives. As affirmed by the World Health Organization (WHO), hand hygiene is the most powerful preventive measure against healthcare-associated infections (HCAIs) and, thus, it has become one of the five key elements of patient safety program. The aim is to assess the effect of implementation of the WHO's Multimodal Hand Hygiene Improvement Strategy among healthcare workers of a tertiary teaching hospital in a developing country. Methods. Hand hygiene compliance was assessed among healthcare workers, according to five defined moments for hand hygiene of the WHO, before and after implementation of the WHO's Multimodal Hand Hygiene Improvement Strategy in fourteen wards of a tertiary teaching hospital in Shiraz, Iran. We used direct observation method and documented the results in WHO hand hygiene observation forms. Results. There was a significant change in compliance before and after implementation of WHO's Multimodal HH Improvement Strategy (29.8\% and 70.98\%, resp.). Conclusions. Implementing WHO hand hygiene program can significantly improve hand hygiene compliance among nurses.
\end{abstract}

\section{Introduction}

Healthcare-associated infection (HCAI) is one of the most important challenges of healthcare systems due to its strong impact on patient's safety and high financial burden [1-4]. In developed countries, the prevalence of HCAI is estimated between $5.1 \%$ and $11.6 \%$ [5]. The costs of HCAIs in the United States are estimated to be about $\$ 6.8$ billion per year [6]. However, most reports of HCAI prevalence from developing countries are above $10 \%$. Consequences of HAIs include increased morbidity, mortality, and expenditure [5]. Hands of healthcare personnel are known to be the main culprit of cross transmission of pathogens in healthcare facilities, and, as stated by the WHO and Centers for Disease Control and Prevention (CDC), $\mathrm{HH}$ is the most effective preventive measure against HAIs. Nonetheless, $\mathrm{HH}$ compliance among healthcare workers is not acceptable, below $40 \%$ globally [3, 7-9]. Noncompliance reasons are surveyed in different studies. They are categorized into individual, group, and institutional levels. The main reasons are the lack of education, being a medical doctor, lack of performance feedback, working in a critical care unit, lack of available or suitable $\mathrm{HH}$ agents, and lack of skin care products [9-12]. Today, $\mathrm{HH}$ has become a major issue of patient safety [6]. In addition to being a key element in standard precautions, $\mathrm{HH}$ has emerged as an important component in specific site infection prevention recommendations recently [13]. In accordance with the first Global Patient Safety Challenge, the WHO published important instructions including guidelines on $\mathrm{HH}$ in healthcare, implementation of the WHO Multimodal $\mathrm{HH}$ Improvement Strategy, and $\mathrm{HH}$ technical reference manual [14]. The aim of these guidelines is to improve $\mathrm{HH}$ practices worldwide by creating a unified description for $\mathrm{HH}$ methods, right moments, and observation process and present multimodal strategies for improvement [14-17].

Due to the lack of $\mathrm{HH}$ observation surveys in developing countries and the few WHO based $\mathrm{HH}$ observation surveys worldwide, we implemented the WHO Multimodal $\mathrm{HH}$ 
Improvement Strategy to assess its feasibility and efficacy in a developing country.

\section{Methods}

This quasi-experimental study was conducted in Nemazee Hospital, a tertiary academic center, between June 2014 and June 2015. It is the largest hospital in the south of Iran (a developing country) and a referral center for neighboring provinces with 1000 beds in 54 wards including emergency, intensive care, surgical, internal medicine, and pediatrics subspecialties. We implemented the WHO's Multimodal $\mathrm{HH}$ Improvement Strategy and assessed the compliance of $\mathrm{HH}$ before and after the interventions.

The Multimodal HH Improvement Strategy consists of five key elements that are (1) system change to ensure access of healthcare workers to $\mathrm{HH}$ facilities with emphasis on availability of alcohol-based hand rub (ABHR) formulations at the point of care, (2) ongoing training and education, (3) evaluation of practices and feedback, (4) reminders at the workplace, and (5) providing a climate of safety through institution [14].

The entire project included five steps: (1) facility preparedness, (2) baseline evaluation, (3) implementation, (4) followup evaluation, and (5) ongoing planning and review cycle [14].

In step (1), facilities were prepared. The human and financial resources were obtained, key leadership and its deputy were identified, sources were evaluated, and the strategy for the whole program was clearly defined. Hand washing sinks were adequate (one sink for up to 6 beds) and were equipped with unmedicated soap, but paper towels were not widely available. Commercially produced ABHR dispensers were located out of each room and thus there was no access to ABHR at the point of care. Educational sessions on $\mathrm{HH}$ were conducted only for nursing staff occasionally and although most hospital's medical doctors were not aware of $\mathrm{HH}$ importance and right techniques, due to cultural drawbacks, no educational session was held for them.

Baseline evaluation of $\mathrm{HH}$ compliance was performed, using the WHO's direct observation method. As the direct observation method is time-consuming and also due to the lack of sufficient personnel, we randomly selected 14 wards from 54 wards. All medical departments of the hospital (emergency, internal, pediatric, intensive care, and surgical) were included in these selected wards. Observation sessions were performed by 2 general medical doctors who were working as infection prevention and control practitioners and were trained by scientific- research deputy of infection prevention and control unit. The training course consisted of 2 parts. In the first part, the WHO's training Power Point slides for observers were taught during a period of about 2 hours, followed by 2 hours for completing observation forms according to WHO's sample video clips [18]. Observers were also taught important points from WHO's $\mathrm{HH}$ technical reference manual. In the second part, experimental form completion took place in wards under the supervision of a senior observer.
The WHO's direct observation form is based on "My

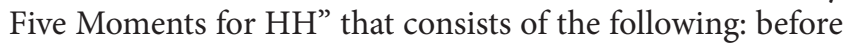
patient contact, before aseptic procedure, after body fluid exposure risk, after patient contact, and after contact with patient surroundings as $\mathrm{HH}$ indications [15]. A positive or negative $\mathrm{HH}$ action, whether hand washing or hand rubbing, was recorded provided that it related to an indication. Opportunity is defined as the time $\mathrm{HH}$ should happen and it must relate to at least one $\mathrm{HH}$ indication. The compliance is calculated by dividing positive actions by opportunities. $\mathrm{HH}$ practice of healthcare workers was monitored in 30-45minute sessions (open wards and wards with multibed rooms, resp.). As it is recommended not to observe more than two healthcare workers simultaneously, $\mathrm{HH}$ opportunities were recorded during care sequences and, on the other hand, there was a time shortage for each session and a limited number of healthcare workers of a ward were observed. All four defined professional categories of data were recorded with focus on nurses due to their prominent role in healthcare activities. During the direct observations, the healthcare workers were aware of being observed since they knew the infection control practitioners. Each observer conducted only two sessions daily. To save time and also gather a greater number of opportunities, $\mathrm{HH}$ monitoring was performed at medication time when $\mathrm{HH}$ opportunities had the highest density. Each period of data collection lasted 3-4 weeks.

The average number of observed opportunities was 16 per ward. There was no performance feedback during the observation periods. Collected data were anonymous and were kept confidential.

In step (3), the improvement program was implemented. Bed mounted ABHR holders were designed and provided. Local production of ABHR according to WHO ethanol based formula commenced due to financial reasons and each bed was equipped with $\mathrm{ABHR}$ and thus alcohol-based ABHR became available at the point of care and paper towels became more available. Visual $\mathrm{HH}$ color posters in different sizes were provided that showed the five moments for $\mathrm{HH}$ and right techniques. Posters were placed in the most visible places in wards (in front of nursing stations). Five billboards were dedicated to infection prevention and control unit and were placed in strategic zones within the hospital. Infection prevention and control points with special emphasis on $\mathrm{HH}$ role in prevention of HAI, promotional messages, and right techniques were displayed on boards. To better attract healthcare workers attention, many messages were colorful, cartoon-like. or comic. The messages were changed monthly.

Nursing staff had to enroll in infection prevention and control educational courses (including $\mathrm{HH}$ topics as the main part) twice a year. The content was based on WHO's training slides. Supervisors had an extra educational session. For the first time in our hospital, infection prevention and control educational sessions were conducted for medical students before their clinical training and for staff medical doctors annually. An infection prevention and control booklet was provided and newly employed nurses had to read it thoroughly and obtain at least 70 (out of 100) in the examination based on its content; otherwise, they had to prepare for another examination. 
TABLE 1: Hand hygiene compliance by hand hygiene indications (events) before and after the intervention regardless of professions.

\begin{tabular}{|c|c|c|c|}
\hline Hand hygiene indications & & Before intervention & After intervention \\
\hline \multirow{2}{*}{ Before touching a patient } & Action, $N(\%)$ & $13(31)$ & $85(85.8)$ \\
\hline & Indication, $N$ & 42 & 99 \\
\hline \multirow{2}{*}{ Before clean/aseptic procedure } & Action, $N(\%)$ & $13(16.4)$ & $3(100)$ \\
\hline & Indication, $N$ & 79 & 3 \\
\hline \multirow{2}{*}{ After body fluid exposure risk } & Action, $N(\%)$ & $11(50)$ & $6(46.1)$ \\
\hline & Indication, $N$ & 22 & 13 \\
\hline \multirow{2}{*}{ After touching a patient } & Action, $N(\%)$ & $32(54.2)$ & $31(73.8)$ \\
\hline & Indication, $N$ & 59 & 42 \\
\hline \multirow{2}{*}{ After touching patient surroundings } & Action, $N(\%)$ & $17(24.6)$ & $13(44.8)$ \\
\hline & Indication, $N$ & 69 & 29 \\
\hline
\end{tabular}

Teaching rounds were conducted with emphasis on intensive care units due to lower compliance rate according to prior studies $[4,10,12,19]$. In these rounds, five moments for $\mathrm{HH}$ and right techniques were practiced. The program was announced to medical and nursing key leaders during separate sessions. Senior hospital manager approved the project and it became one of the hospital priorities.

In step (4), after 12 months, follow-up evaluation for assessment of program effectiveness was performed. Observation feedback was announced through hospital quality improvement sessions.

Data were analyzed using SPSS version 18 and $p$ value less than 0.05 was considered statistically significant.

\section{Results}

In the present study, we assessed the healthcare personnel's $\mathrm{HH}$ compliance in 14 wards of the hospital using the WHO's method before and after the implementation of WHO's $\mathrm{HH}$ improvement program through the institution [10, 17]. According to this method, an opportunity is defined as the proper time for $\mathrm{HH}$ according to "My Five Moments for HH” during the care sequences $[10,13,18]$. Also, we recorded actions, both hand washing and hand rubbing, according to five indications: before patient contact, before an aseptic task, after risk of exposure to body fluid, after patient contact, and after contact with patient surroundings. The compliance is calculated by dividing the number of positive actions by the number of opportunities (not indications). Before the intervention, a total of 255 opportunities (nurses: 243; auxiliaries (orderlies): 6; medical doctors: 3; others: 3 ) and 76 actions for $\mathrm{HH}$ were recorded. After the intervention, the compliance rate improved from 29.8 to $70.98 \%$ (193 opportunities and 137 actions).

Table 1 shows that compliance with $\mathrm{HH}$ increased after

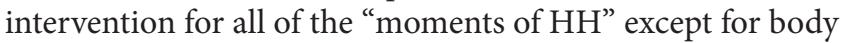
fluid exposure risk. Also, for ease of understanding, these differences are displayed in Figure 1.

The $\mathrm{HH}$ compliance rates before and after the intervention are presented in Table 2.

Due to the lack of data (small number of recorded opportunities) related to auxiliaries and medical doctors, the

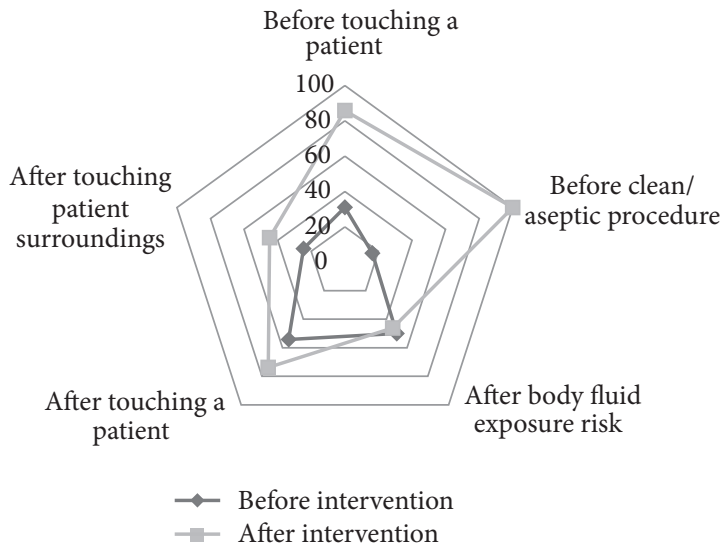

FIGURE 1: The radar chart of hand hygiene compliance by indications, before and after the intervention.

results of compliance ratio in nurses before and after the implementation of the program are compared.

As shown in Table 2, there is a substantial increase in observed compliance with $\mathrm{HH}$ practices after completing the implementation of the $\mathrm{HH}$ improvement program (from $29.6 \%$ to 72.7$)$. This difference was confirmed using $\chi^{2}$ test $(p<0.001)$.

Figure 2 displays the changes in $\mathrm{HH}$ compliance of nurses per ward. Based on this result, the greatest difference in proportions is related to ward " $G$ " (0\% versus $64.71 \%)$ and then ward " $C$ " (16\% versus $75 \%)$ which were a surgical ward and an emergency ward, respectively.

Table 3 represents the observed opportunities and actions, both hand washing and hand rubbing, in different professional categories after the intervention. According to this table, nurses and auxiliaries contribute to $\mathrm{HH}$ compliance in $72.6 \%$ and $65.15 \%$ of their opportunities, respectively. Also, there are large differences between the proportions of hand rubbing and hand washing, as it seems that hand rubbing is much more popular than hand washing among the personnel (Figure 1).

Change of system by making ABHRs available at the point of care considerably improved hand rubbing proportion among nurses $(p<0.001)$ (Figure 3$)$. 
TABLE 2: Comparison of hand hygiene compliance of nurses.

\begin{tabular}{lcccc}
\hline & Opportunities, $N$ & Compliance, $\%(95 \%$ CI $)$ & $\chi^{2}$ test statistic & $p$ value \\
\hline Before intervention & 243 & $29.6(23.86,35.34)$ & 55.63 \\
After intervention & 110 & $72.7(64.37,81.02)$ & & $<0.001$ \\
\hline
\end{tabular}

TABLE 3: Observed opportunities and actions for hand hygiene after the intervention.

\begin{tabular}{lcccc}
\hline Professional category & Opportunities, $N$ & Hand washing, $N(\%)$ & Hand rubbing, $N(\%)$ & Compliance rate, \% (95\% CI) \\
\hline Nurse & 110 & $7(6.3)$ & $73(66.3)$ & $72.7(64.37,81.02)$ \\
Auxiliary & 66 & $5(7.5)$ & $38(57.5)$ & $65.15(53.65,76.65)$ \\
Medical doctor & 17 & $0(0 \%)$ & $14(82.3)$ & $82.35(64.23,100.47)$ \\
Total & 193 & $12(6.2)$ & $71(64.58,77.38)$ \\
\multicolumn{4}{c}{ Total actions $=137$} \\
\end{tabular}

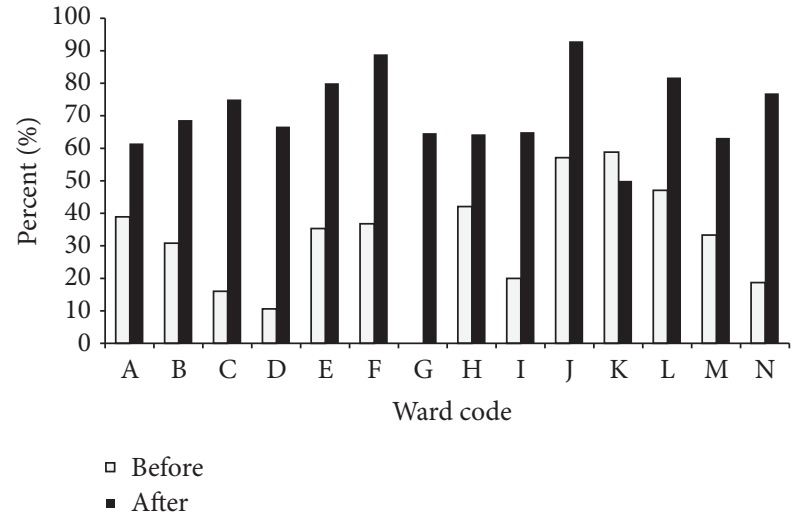

FIgure 2: Hand hygiene compliance of nurses per ward. (A) ICU, (B) Internal Pediatrics, (C) Emergency, (D) Surgical Pediatrics, (E) Internal Pediatrics, (F) ICU, (G) Surgical, (H) Surgical, (I) Internal, (J) Internal, (K) ICU, (L) Internal, (M) Internal, and (N) ICU.

\section{Discussion}

$\mathrm{HH}$ practice is the single most effective measure for prevention and reduction of HCAIs [14, 16, 20].

In a recent interventional survey, healthcare-associated infection rate declined significantly and constantly from 4.8 to 3.3 ( $p<0.01)$ per 1000 inpatient days, after implementation of a hospital-wide $\mathrm{HH}$ initiative that led to a marked improvement in staff behavior [21].

Such behavioral changes toward $\mathrm{HH}$ improvement need multimodal interventions including providing ABHRs and continuous educational programs as well as strong support by healthcare administrators [13]. In the present study, it was shown that implementation of $\mathrm{WHO} \mathrm{HH}$ improvement program led to a significant increase in $\mathrm{HH}$ compliance rates in nurses of a large academic hospital.

In a quasi-experimental multicenter study, WHO strategies, including multimodal interventions, were implemented in a stepwise fashion and hand hygiene compliance of healthcare workers was assessed before and after the interventions. Furthermore, long-term sustainability of strategic activities was evaluated two years later [6]. Compliance was

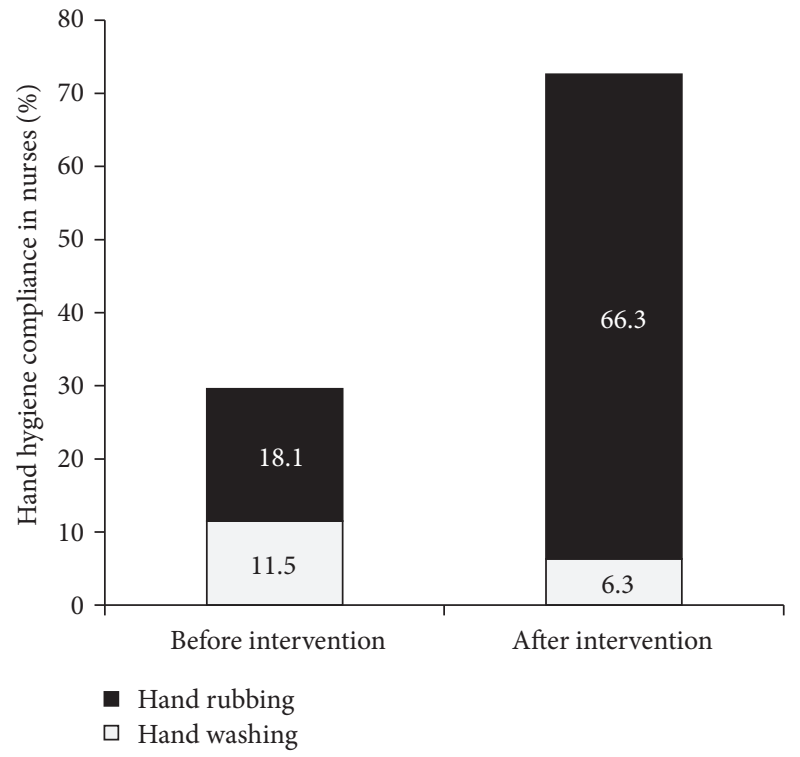

FIGURE 3: Effect of system change on the proportion of hand hygiene techniques among nurses.

defined as the proportion of predefined opportunities met by hand hygiene actions (hand washing or hand rubbing). The reported compliance increased from $51.0 \%$ before the intervention (95\% CI: $45.1-56.9$ ) to $67.2 \%$ after the intervention (95\% CI: 61.8-72.2). In the second assessment 2 years after the intervention, ongoing $\mathrm{HH}$ activities with sustained or further improvement were reported from all enrolled centers.

Some reports denote various compliance rates for the five indications of $\mathrm{HH}$ that are sometimes statistically different [10]. A quasi-experimental research between 2006 and 2008 at six pilot sites in Italy, Pakistan, Mali, Costa Rica, and Saudi Arabia (55 departments in 43 hospitals within these countries) stated that $\mathrm{HH}$ compliance with indications protecting the patient was significantly lower than indications that prevent healthcare workers from contamination and being infected; the compliance of "before patient contact" and "before clean and aseptic tasks" was the lowest and the compliance of "after exposure risk with body fluids" and 
"after patient contact" was the highest [6]. However, the tendency to self-protect that is reported by other studies was not evident in our study $[9,14,22,23]$.

A remarkable finding in the present study was improvement of $\mathrm{HH}$ compliance at all of the "moments for $\mathrm{HH}^{\circ}$ except "after body fluid exposure risk." The explanation could be the small number of observed opportunities of "after body fluid exposure" during the study period.

An observational survey [10] in 5 intensive care units (ICUs) and among 242 healthcare workers at a university hospital used the WHO's "five moments for HH" as the basis for observations. The overall reported noncompliance rate was $58 \%$ and the lowest $\mathrm{HH}$ compliance rates among opportunities were "before touching a patient" (37.3\%) and "after touching a patient or the patient's surroundings" (45.3\%). Among the multiple factors associated with noncompliance, the odd ratio of performance of $\mathrm{HH}$ "before patient contact" was the highest (OR: 4.5).

The compliance to "before clean/aseptic procedure" was poor in our center in baseline evaluation and before intervention. This finding was presented by WHO reports from other countries $[3,11,16]$. This poor condition changed dramatically after intervention and the best result in five opportunities after the intervention was observed for doing $\mathrm{HH}$ "before clean/aseptic procedure." This may be due to more intense education and emphasis on it. However, this significant improvement of the mentioned indication compliance is not in concordance with other studies and shows the variable rates of compliance between indications, both before and after interventions among researches [10, 24-29].

One factor that could affect any $\mathrm{HH}$ improvement program is the type of ward and nature. A few investigations that have specifically assessed $\mathrm{HH}$ compliance in surgical wards showed the lower rate of implementation of $\mathrm{HH}$ in these wards $[7,29,30]$, a rate that could be even $59 \%$ lower than medical wards [25]. Nevertheless, based on our results, the greatest advance in compliance after the intervention was related to a surgical ward ( $0 \%$ before versus $64.71 \%$ after) and then an emergency ward (16\% before versus $75 \%$ after).

Another involved factor in the $\mathrm{HH}$ practice is the professional group. Medical doctors have generally lower $\mathrm{HH}$ compliance rates than nurses. Based on one study, about half of the medical doctors thought that $\mathrm{HH}$ is necessary after patient contact and only one-third of them believed that $\mathrm{HH}$ is mandatory before patient contact [31].

It is noteworthy that being a medical doctor (OR 1.712, 95\% CI: 1.126-2.989) could be a significant risk factor for $\mathrm{HH}$ noncompliance in the hospital after adjusting for other potential risk factors [11].

In a multicenter study done in 5 countries, medical doctors had the lowest and nurses had the highest compliance before the intervention except for Costa Rica and Mali. The $\mathrm{HH}$ practice remained better in nurses than in medical doctors across all test sites, except for Mali [6].

Before intervention, $\mathrm{HH}$ compliance of medical doctors was $11.5 \%$ (52 opportunities and 6 actions) which was much lower than of the nurses $(29.62 \%)$ in our study. Contrary to other studies, after intervention, $\mathrm{HH}$ compliance of nurses (72.6\%), auxiliaries (65.15\%), and medical doctors $(82.35 \%)$ rose dramatically $[1,5,6,9,12,15,32-34]$. This finding of the present study could be probably due to the small number of observed opportunities among medical doctors or their better recall of previous knowledge after educational intervention.

Also, there are considerable differences between the proportions of hand rubbing and hand washing as it seems that hand rubbing is much more popular than hand washing among the personnel. This was shown in a study by Allegranzi et al. [6]. They noted a significant increase in hand rubbing method and it was the favored way of hand hygiene, after intervention, in the majority of sites. Despite the significant statistical $\mathrm{HH}$ improvement among nurses, this study was prone to "Hawthorne effect" due to the direct observation method and short follow-up period.

\section{Conclusion}

The fact that using $\mathrm{WHO} \mathrm{HH}$ promotion strategy leads to an improvement of $\mathrm{HH}$ practice is shown in the present and other studies [35]. It is our belief that such interventional program in a large pilot hospital and in a developing country could serve as an acceptable model for other initiatives. The significance of $\mathrm{HH}$ and commitment to it should also be better taught worldwide, especially in countries with lower compliance and higher HCAIs. Hand hygiene promotion also demands more local and oriented researches. Our study revealed poor $\mathrm{HH}$ compliance among medical doctors before the intervention, but a significant improvement after the intervention. Further investigations with sufficient sample size are needed to clarify the reasons of noncompliance among medical doctors and assess the effectiveness of the multimodal strategy in this professional group.

\section{Abbreviations \\ CDC: Centers for Disease Control and Prevention \\ HCAI: Healthcare-associated infection \\ $\mathrm{HH}$ : Hand hygiene \\ WHO: World Health Organization \\ ABHR: Alcohol-based hand rub.}

\section{Competing Interests}

The authors declare that they do not have any competing interests.

\section{Acknowledgments}

This article is based on Dr. Golnar Sajadi's thesis (no. 95-0101-11581). The authors wish to thank all members of hand hygiene improvement program, especially the matron and nursing supervisors, for their cooperation in the implementation of the strategies; Clinical Research Improvement Center of Nemazee Hospital, in particular Maryam Gholami for her consultation and cooperation in data analyses and Parisa Chamanpara for data analyses and writing the result section and all healthcare workers of the hospital for their 
endeavors to improve patient safety; and Hassan Khajehei for copyediting the manuscript.

\section{References}

[1] F. Shiva, M. Kamali, F. Shirvani et al., "Hand hygiene compliance by the health care staff in a pediatric hospital," Archives of Pediatric Infectious Diseases, vol. 2, no. 4, Article ID e18909, 2014.

[2] B. C. C. Lam, J. Lee, and Y. L. Lau, "Hand hygiene practices in a neonatal intensive care unit: a multimodal intervention and impact on nosocomial infection," Pediatrics, vol. 114, no. 5, pp. e565-e571, 2004.

[3] V. Erasmus, T. J. Daha, H. Brug et al., "Systematic review of studies on compliance with hand hygiene guidelines in hospital care," Infection Control and Hospital Epidemiology, vol. 31, no. 3, pp. 283-294, 2010.

[4] A. Huis, L. Schoonhoven, R. Grol, R. Donders, M. Hulscher, and T. van Achterberg, "Impact of a team and leaders-directed strategy to improve nurses' adherence to hand hygiene guidelines: a cluster randomised trial," International Journal of Nursing Studies, vol. 50, no. 4, pp. 464-474, 2013.

[5] World Health Organization WHO, "The burden of health care-associated infection worldwide. A summary," 2013, http:// www.who.int/gpsc/country_work/summary_20100430_en.pdf.

[6] B. Allegranzi, A. Gayet-Ageron, N. Damani et al., "Global implementation of WHO's multimodal strategy for improvement of hand hygiene: a quasi-experimental study," The Lancet Infectious Diseases, vol. 13, no. 10, pp. 843-851, 2013.

[7] A. Lee, A. Chalfine, G. L. Daikos et al., "Hand hygiene practices and adherence determinants in surgical wards across Europe and Israel: a multicenter observational study," American Journal of Infection Control, vol. 39, no. 6, pp. 517-520, 2011.

[8] A. R. Marra, L. R. Guastelli, C. M. P. de Araújo et al., "Positive deviance: a program for sustained improvement in hand hygiene compliance," American Journal of Infection Control, vol. 39, no. 1, pp. 1-5, 2011.

[9] D. Pittet, S. Hugonnet, S. Harbarth et al., "Effectiveness of a hospital-wide programme to improve compliance with hand hygiene," The Lancet, vol. 356, no. 9238, pp. 1307-1312, 2000.

[10] S. Alsubaie, A. B. Maither, W. Alalmaei et al., "Determinants of hand hygiene noncompliance in intensive care units," American Journal of Infection Control, vol. 41, no. 2, pp. 131-135, 2013.

[11] A. A. Mahfouz, M. N. El Gamal, and T. A. Al-Azraqi, "Hand hygiene non-compliance among intensive care unit health care workers in aseer central hospital, South-Western Saudi Arabia," International Journal of Infectious Diseases, vol. 17, no. 9, pp. e729-e732, 2013.

[12] D. Pittet and J. M. Boyce, "Hand hygiene and patient care: pursuing the Semmelweis legacy," The Lancet Infectious Diseases, vol. 1, pp. 9-20, 2001.

[13] B. Allegranzi and D. Pittet, "Role of hand hygiene in healthcareassociated infection prevention," Journal of Hospital Infection, vol. 73, no. 4, pp. 305-315, 2009.

[14] World Health Organization, Guide to Implementation. A Guide to the Implementation of the WHO Multimodal Hand Hygiene Improvement Strategy, WHO, Geneva, Switzerland, 2009.

[15] World Health Organization, Hand Hygiene Technical Reference Manual, World Health Organization, Geneva, Switzerland, 2009, http://www.who.int/gpsc/5may/tools/evaluation_ feedback/en/index.html.
[16] World Health Organization, WHO Guidelines on Hand Hygiene in Health Care. First Global Patient Safety Challenge Clean Care is Safer Care, 2009.

[17] H. Sax, B. Allegranzi, M.-N. Chraïti, J. Boyce, E. Larson, and D. Pittet, "The World Health Organization hand hygiene observation method," American Journal of Infection Control, vol. 37, no. 10, pp. 827-834, 2009.

[18] World Health Organization, "Tools for training and education," 2009, http://www.who.int/gpsc/5may/tools/training_education/ en/.

[19] D. Pittet, B. Allegranzi, H. Sax et al., "Evidence-based model for hand transmission during patient care and the role of improved practices," The Lancet Infectious Diseases, vol. 6, no. 10, pp. 641$652,2006$.

[20] E. K. Kretzer and E. L. Larson, "Behavioral interventions to improve infection control practices," American Journal of Infection Control, vol. 26, no. 3, pp. 245-253, 1998.

[21] K. B. Kirkland, K. A. Homa, R. A. Lasky, J. A. Ptak, E. A. Taylor, and M. E. Splaine, "Impact of a hospital-wide hand hygiene initiative on healthcare-associated infections: results of an interrupted time series," BMJ Quality \& Safety, vol. 21, no. 12, pp. 1019-1026, 2012.

[22] V. C. C. Cheng, J. W. M. Tai, S. K. Y. Ho et al., "Introduction of an electronic monitoring system for monitoring compliance with Moments 1 and 4 of the WHO 'My 5 Moments for Hand Hygiene' methodology,' BMC Infectious Diseases, vol. 11, article 151, 2011.

[23] A. Stewardson, H. Sax, S. Longet-Di Pietro, and D. Pittet, "Impact of observation and analysis methodology when reporting hand hygiene data," Journal of Hospital Infection, vol. 77, no. 4, pp. 358-359, 2011.

[24] D. Pittet, P. Mourouga, and T. V. Perneger, "Compliance with handwashing in a teaching hospital," Annals of Internal Medicine, vol. 130, no. 2, pp. 126-130, 1999.

[25] F. I. McArdle, R. J. Lee, A. P. Gibb, and T. S. Walsh, "How much time is needed for hand hygiene in intensive care? A prospective trained observer study of rates of contact between healthcare workers and intensive care patients," Journal of Hospital Infection, vol. 62, no. 3, pp. 304-310, 2006.

[26] B. L. Thompson, D. M. Dwyer, X. T. Ussery, S. Denman, P. Vacek, and B. Schwartz, "Handwashing and glove use in a longterm-care facility," Infection Control \& Hospital Epidemiology, vol. 18, no. 2, pp. 97-103, 1997.

[27] S. Harbarth, D. Pittet, L. Grady, and D. A. Goldmann, "Compliance with hand hygiene practice in pediatric intensive care," Pediatric Critical Care Medicine, vol. 2, no. 4, pp. 311-314, 2001.

[28] M. Whitby and M.-L. McLaws, "Methodological difficulties in hand hygiene research," Journal of Hospital Infection, vol. 67, no. 2, pp. 194-195, 2007.

[29] D. Pittet, A. Simon, S. Hugonnet, C. L. Pessoa-Silva, V. Sauvan, and T. V. Perneger, "Hand hygiene among physicians: performance, beliefs, and perceptions," Annals of Internal Medicine, vol. 141, no. 1, pp. 1-8, 2004.

[30] P. A. Lipsett and S. M. Swoboda, "Handwashing compliance depends on professional status," Surgical Infections, vol. 2, no. 3, pp. 241-245, 2001.

[31] R. Sharir, N. Teitler, I. Lavi, and R. Raz, "High-level handwashing compliance in a community teaching hospital: a challenge that can be met!" Journal of Hospital Infection, vol. 49, no. 1, pp. 55-58, 2001. 
[32] A. G. Venier, D. Zaro-Goni, M. Pefau et al., "Performance of hand hygiene in 214 healthcare facilities in South-Western France," Journal of Hospital Infection, vol. 71, no. 3, pp. 280-282, 2009.

[33] S. Hugonnet, T. V. Perneger, and D. Pittet, "Alcohol-based handrub improves compliance with hand hygiene in intensive care units," Archives of Internal Medicine, vol. 162, no. 9, pp. 1037-1043, 2002.

[34] B. Allegranzi, S. B. Nejad, C. Combescure et al., "Burden of endemic health-care-associated infection in developing countries: systematic review and meta-analysis," The Lancet, vol. 377, no. 9761, pp. 228-241, 2011.

[35] J. Tai, D. Pittet, W. Seto, V. Cheng, and P. Ching, "O076: impact of the implementation of the who hand hygiene promotion strategy in the Hong Kong pilot site: 2006-2012," Antimicrobial Resistance and Infection Control, vol. 2, no. 1, p. 1, 2013. 


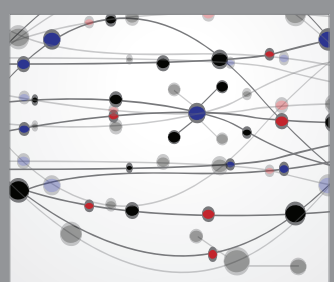

The Scientific World Journal
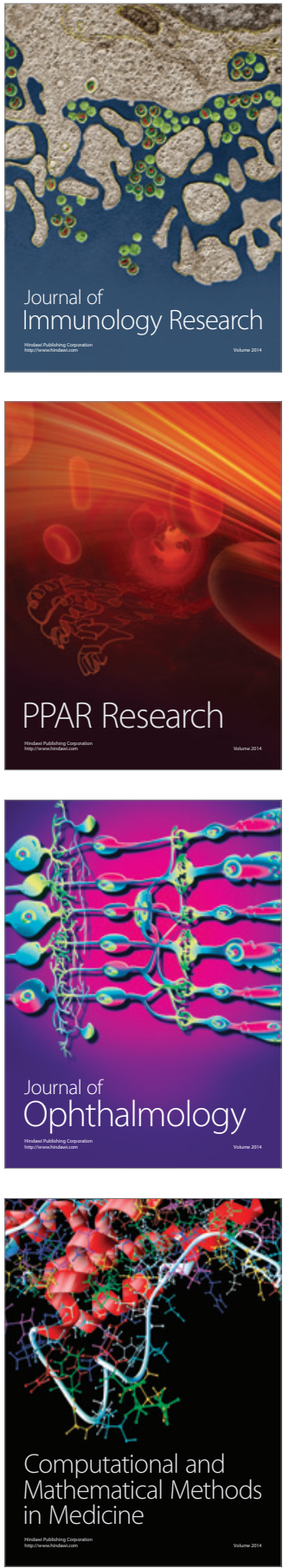

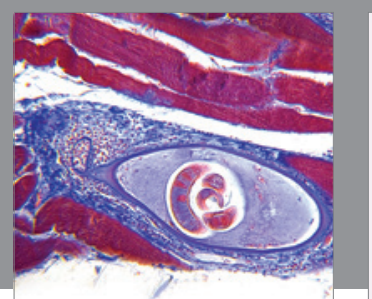

Gastroenterology Research and Practice

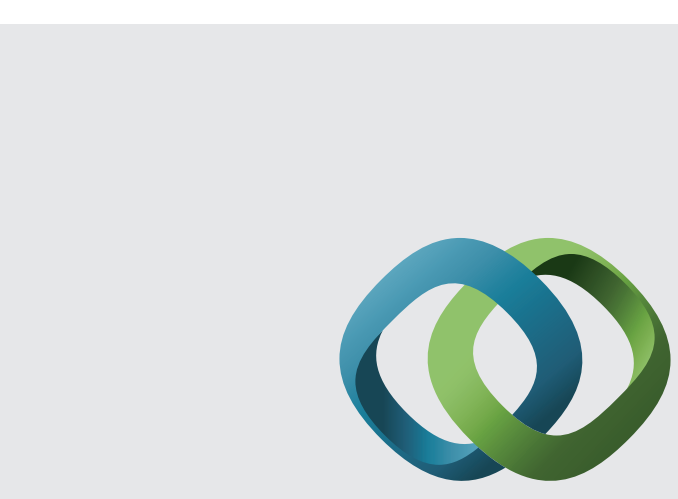

\section{Hindawi}

Submit your manuscripts at

http://www.hindawi.com
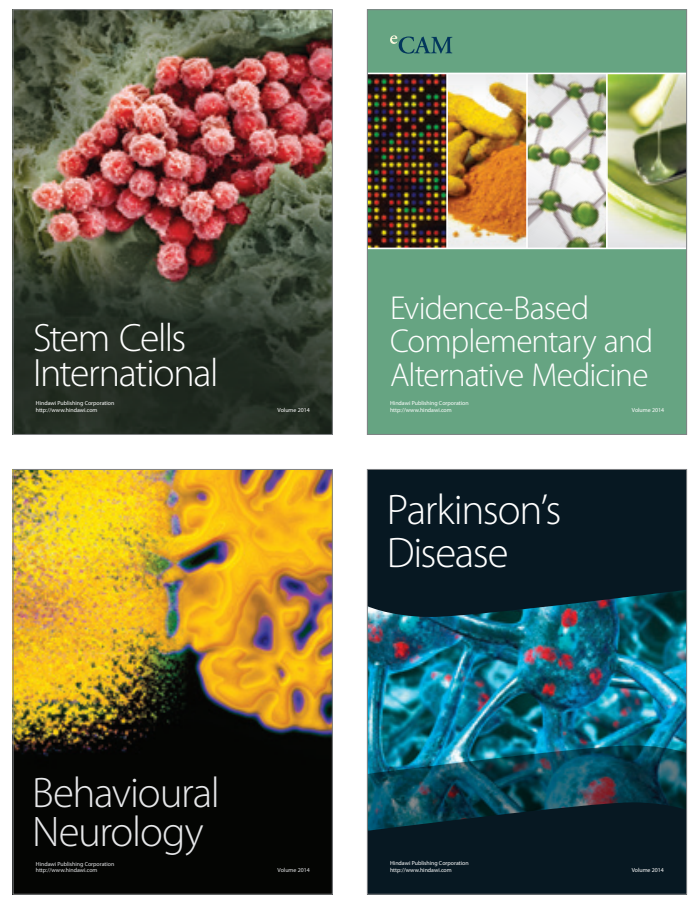
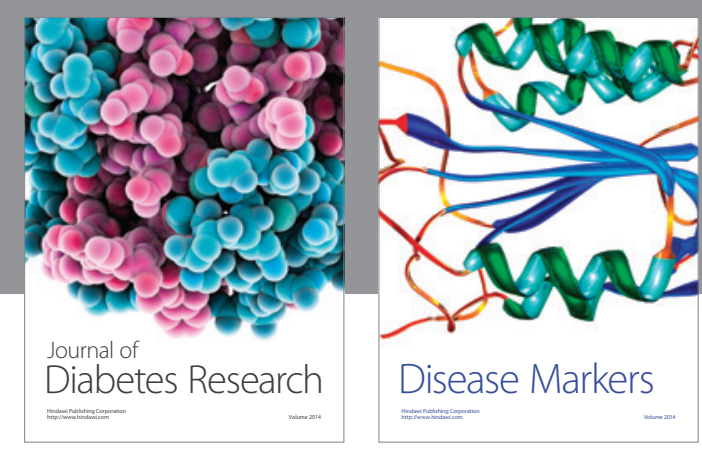

Disease Markers
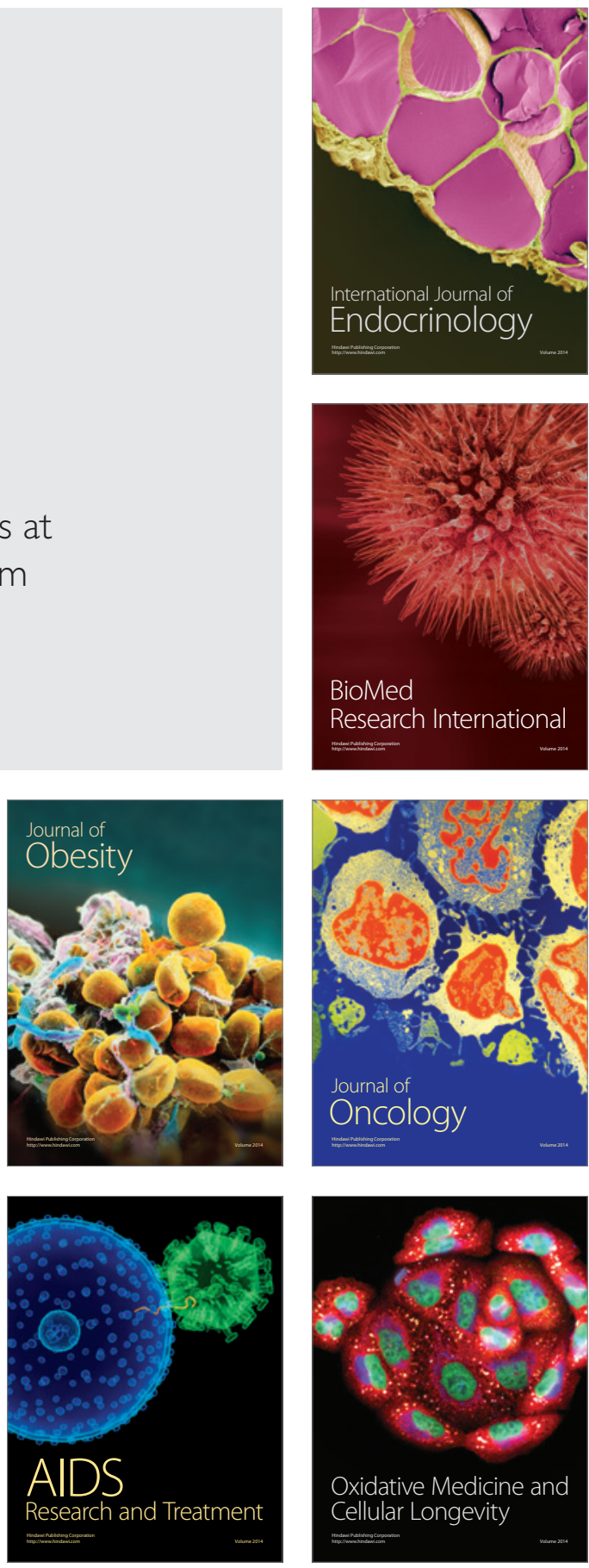